\title{
The Queer Spaces of BDSM and Non-monogamy
}

\author{
Charlotta Carlström, \\ Malmö University (Sweden) \\ charlotta.carlstrom@mau.se \\ Catrine Andersson \\ Malmö University (Sweden)
}

\begin{abstract}
Based on interviews and ethnographic fieldwork within BDSM communities in Sweden, this article focuses on links between non-monogamy and BDSM. Drawing on Halberstam's concept of queer space, the following questions are investigated: What are the connections between BDSM and non-monogamous communities? How does interaction between BDSM and non-monogamous practices create non-normative logic? The transgression of one norm makes it easier to transgress other norms as well, providing opportunities to find new ways of organizing relationships beyond the norms of monogamy. In order for an individual to be able to fully explore kinks in BDSM practices and at the same time respect the boundaries of a partner, nonmonogamy emerges as one logical answer.
\end{abstract}

\section{Introduction}

Based on interviews and ethnographic fieldwork within several BDSM communities in Sweden, this article focuses on links between non-monogamy and BDSM (bondage and discipline, dominance and submission, and sadism and masochism). Earlier studies by Bauer (2008, 2010), Sheff (2005), and Sheff and Hammers (2011) have explored connections between these communities and point to ideals shared by both communities, for instance, concerning the importance of communication. The present article contributes to this emerging discussion by focusing on the following questions: What are the connections between BDSM and nonmonogamous communities? In what ways does non-monogamy become important for BDSM practice? How does interaction between BDSM and non-monogamous practices create nonnormative logic? The article contributes to existing scholarship on BDSM by exploring nonmonogamous patterns of intimacy within BDSM communities. It also contributes to research on non-monogamous communities by investigating skills that BDSM practitioners have developed concerning communication and consent, which may perform similar functions in nonmonogamous relationships. In this study, we use the concept of queer space (Halberstam, 2005) to explore the material. This concept allows a discussion on how communities develop nonnormative logics, transcending the ideals of normality, the reproductive family, and the stable couple. In a society where coupling is of paramount importance for how we live our lives, as well as for how we structure the world, the concept of queer space can provide greater understanding for experiences of living outside the frames of normative ideals of relationships and sexuality.

The abbreviation BDSM describes a variety of behaviors that involve an implicit or explicit erotic power exchange. BDSM includes a wide range of activities, practices, positions 
and relation types, but also various meanings and purposes (Barker, 2013). It is built on fantasies, daydreams, thoughts and feelings, and the different practices stress taboos, boundaries, prohibitions and social norms (Newmahr, 2010; Weiss, 2011). Practitioners adopt dominant, sadist, submissive, or masochistic roles. If a person wants to be both dominant and submissive, the person is called a switch. For some practitioners, the roles are limited to sexual role-play, while others adopt the roles at all times, also called 24/7 relationships.

In recent years, the research field concerned with BDSM has diversified and studies have looked at these practices from many different angles. Recent studies thus explore issues of communication and consent (Barker, 2013; Bauer, 2008), gender and BDSM (Carlström, 2017; Yost, 2007), as well as BDSM in relation to the surrounding society (Beckmann, 2001; Taylor \& Ussher, 2001; Weiss, 2006). Several studies show that BDSM cannot be explained by psychopathology (see for example Richters et al., 2008; Wismeijer \& van Assen, 2013; Williams et al., 2017). In their investigation of kink activities as avenues for exploring gender identity and sexual orientation, Sprott and Hadcock (2017) emphasize that kink communities and kink activities can be important elements in healing from shame, isolation and loss.

We use "non-monogamy” as an umbrella concept for a multitude of practices transgressing norms of monogamy. Many of the informants in this study identify with nonmonogamy and use concepts related to non-monogamy to describe their practices, but other ways of conceptualizing non-monogamy also appear in the material, such as living in triads, "borrowing” or simply "practicing” with someone other than one’s partner. Previous research has focused on various areas related to non-monogamy, such as sexual orientation (Tweedy, 2011; Haupert et al., 2017), agreements and trust (Wosick-Correa, 2010), emotions and intimacy (Klesse, 2017), media representation (Rambukkana, 2015), and attitudes toward non-monogamy (Séguin, 2017). Several studies (Anapol, 2010; Barker \& Langdridge, 2010) point to experiences of discrimination and stigma in relation to non-monogamy. Relatively little research has investigated the relationship between BDSM and non-monogamy, but there are a few studies that deal with the topic. Bauer (2010) has investigated non-monogamous relationships within the BDSM community and notes that "BDSM queers have developed a sexual culture that produces greater awareness of diverse sexual needs in combination with a higher priority on getting them met” (p. 151). Sheff and Hammers (2011) have investigated race, class, and education among polyamorists and kinksters. Finally, an article by Barker (2005) focuses on activism when discussing non-monogamy and BDSM.

\section{Methods}

The first author conducted ethnographic fieldwork in 2012 and 2013 within different BDSM communities in Sweden. The fieldwork included interviews, observation and participation in meetings, workshops, pub evenings and club ventures, and resulted in interviews with a total of 29 persons defining themselves as BDSM practitioners, of which 17 defined themselves as polyamorous or non-monogamous. The informants' ages were between 20 and 60 . They lived in cities, smaller towns, and in rural areas in different parts of Sweden. Fourteen of them identified as women, fourteen as men, and one as non-binary. Nine identified as dominant and/or sadists, thirteen as submissive and/or masochists, and seven as switches. Twenty of the informants had a university education. Interviews were transcribed in full. We analyzed data 
using a qualitative analytical method inspired by thematic analysis as described by Hammersley and Atkinson (1983). We then interpreted the different categories and components that were prominent in the material in relation to theoretical perspectives and previous research in the field. The project complies with the ethical guidelines of the Swedish Research Council (Codex, 2012) and was reviewed by the Regional Ethical Review Board.

\section{BDSM and Non-monogamous Scenes: Queer Spaces}

The informants describe the relationship between non-monogamy and BDSM in a variety of ways, but several refer to common denominators between these practices. The informants often mention the importance of communication. Both BDSM and non-monogamy are characterized by clear negotiations and explicit agreements. Several informants also refer to the permissive atmosphere they experience as something characteristic of the communities. Some explain how their polyamorous desires grew through BDSM activities. A switch woman says: "If you already differ from the norm, it's easier to be open and explore more. If you break one norm you can break another one.” Several informants describe the overlap between the scenes. A polyamorous switch woman points out:

The scenes are blended, probably because of the non-normative approach to relationships. For example, a TPE [total power exchange] relationship is seen as extremely divergent, but also a triangle relationship is different, so it becomes a bit like "we freaks hang out in the corner together." [laughs]

The informant's statements are in line with previous research examining the connection between kink/BDSM communities and non-monogamy. For example, both Barker (2005) and Bauer (2010) suggest that polyamorous and BDSM practitioners share similar values of consensuality, communication, and safety, as well as similar transgressions of standard ways of relating. In Halberstam's words, this could be said to constitute queer spaces-place- and community-making practices that are closely connected to queer subjects, but not in an essential way (Halberstam, 2005). The queer spaces of BDSM and non-monogamy are organizations of community where space is created for living a life that does not fit within the frames of normative ideals of sex and relationships. In a culture strongly characterized by monogamous ideals, BDSM can signify greater freedom because the activities are not seen as infidelity. Practicing BDSM is often of a non-genital character and practitioners may therefore see it as less threatening to primary commitments. Several informants find it important to talk to others about their relations, boundaries, and experiences of jealousy and stigmatization. Many participate in study circles and conversation groups. A submissive woman living with two masters says:

Once a week, I participate in a poly conversation group where we meet and talk about our relationships. We reflect, give and get advice, and support each other. We question and discuss social norms: why do we do what we do? Is it right or wrong and how can we do instead?

The informant here tells us of the importance of having a space in which to discuss and problematize norms and practices. Finding new ways of doing things means going outside the norm, which requires what Halberstam calls “creating non-normative logics” and organizations 
of communities (Halberstam, 2005). In the following, we will go on to discuss how the informants create non-normative logics as they discuss the complex interconnections of BDSM desires and practices with non-monogamy.

\section{BDSM Desire and Non-normative/Non-monogamous Logics}

Some informants live with a primary partner and see others to practice BDSM; some live in triads or with several "slaves." For several, non-monogamy and BDSM are integrated parts of their identity and practitioners understand them as a lifestyle. A submissive woman says:

Poly is my identity. It feels like a basic part of me. BDSM is more like something I do. To be open with my poly identity has been very important to me. Since BDSM is so stigmatized, I choose not to be open about my BDSM preference.

The BDSM community provides various opportunities to practice with other people. Several informants explain that they meet other friends to practice BDSM. One informant, selfdefining as male, dominant, and polyamorous says: "It is more common that BDSM practitioners are poly than that poly people are into BDSM. Many practitioners have several aspects of their practice and need different partners to satisfy different desires." In clubs, it is common that people play together. One purpose in involving additional people in the practice can be to learn. Persons who are skilled and have long experience are often seen as high in the hierarchy. A sadist woman says:

There was a guy at the club who was very good at whipping, and he taught others how to whip. He asked if he could borrow my slave because he thought he had a good body to practice on. I replied that only if I can join because I also wanted to learn. And this was probably the best lesson I ever had.

As mentioned above, one reason that open relationships and non-monogamy are widespread in the BDSM community is that one does not expect to find a single partner who can match all of one's kinks. Asked if there is a difference between BDSM and vanilla sex when it comes to jealousy, a dominant man answers:

Yes, for me there is. There may be BDSM practices I feel uncomfortable to perform or which I don’t master enough, which means I cannot give my partner full commitment. Then it's better my partner practices with someone else. There is a difference when it comes to vanilla sex. Then you want the feeling of being good enough.

As illustrated by these examples, the informants thus tell quite different stories about how BDSM and non-monogamy are intertwined in their practice. In the excerpts above, they mention how both BDSM and non-monogamy are transgressions of norms, making it easier to break more norms after having broken one. One informant describes non-monogamy as an identity, in contrast to BDSM, which for this informant is rather felt to be a practice. Informants refer to BDSM as being a skill that has to be learned by training with others but also comment on how there can be no expectation of matching each of a partner's kinks, so that non-monogamy becomes necessary to make some BDSM practices possible. The various relationships between 
non-monogamy and BDSM expressed in these stories thus constitute a form of non-normative logic that offers possible explanations of the relations between these practices. In order to be able to fully explore kinks in your BDSM practices and at the same time respect the boundaries of your partner, non-monogamy emerges as a logical answer. In the same way, to develop specific skills_-needed, for instance, for whipping — sharing or borrowing slaves can be necessary to fully explore this part of someone’s BDSM practice.

\section{Conclusions}

Queer spaces offer non-normative communities that can counter societal norms of heteronormativity, monogamy, and vanilla sex. In the analysis above, we highlight how the practice of BDSM creates a logic that entails non-monogamy in order to be able to practice all of one's kinks. But this is not the only reason for non-monogamy. The informants also point to how one transgression of norms makes it easier to transgress other norms as well, providing opportunities to find new ways of organizing relationships beyond the norms of monogamy. It is important to understand the relationship between BDSM and non-monogamy since people engaging in non-monogamy and BDSM remain, in Phelan's (2010) words, abject sexual citizens, often unable to claim the relationship rights gained by monogamous vanilla couples. On a societal level, consensual non-monogamies and BDSM practices continue to be demonized, pathologized, and marginalized, with no legal protections for people involved (for example, concerning child-care or relationship status). Broader knowledge of both BDSM and nonmonogamy - and the relationship between the two - may thus contribute to greater understanding and tolerance, helping healthcare professionals to avoid making facile assumptions about the sexual practices of their clients.

\section{References}

Anapol, D. (2010). Polyamory in the 21st century. Lanham, MD: Rowman and Littlefield Publishers.

Barker, M. (2005). On tops, bottoms and ethical sluts: The place of BDSM and polyamory in lesbian and gay psychology. Lesbian and Gay Psychology Review, 6(2), 124-129.

Barker, M. (2013). Gender and BDSM revisited. Reflections on a decade of researching kink communities. Psychology of Women Section Review, 15(2), 20-28.

Barker, M., \& Langdridge, D. (2010). Understanding non-monogamies. New York: Routledge.

Bauer, R. (2008). Transgressive and transformative gendered sexual practices and white privileges: The case of the dyke/trans BDSM communities. Women's Studies Quarterly, 36(3), 233-253. https://doi.org/10.1353/wsq.0.0100.
Bauer, R. (2010). Non-Monogamy in queer BDSM communities: Putting the sex back into alternative relationship practices and discourse. In M. J. Barker \& D. Langdridge (Eds.), Understanding non-monogamies (pp. 142-153). New York: Routledge

Beckmann, A. (2001). Deconstructing myths: The social construction of "sadomasochism" versus "subjugated knowledges” of practitioners of consensual "SM.” Journal of Criminal Justice and Popular Culture, 8(2), 66-95.

Carlström, C. (2017). Gender equal BDSM practice-a Swedish paradox? Psychology \& Sexuality, 8(4), 268-279.

Codex (2012). Forskningsetiska principer inom humanistisk - samhällsvetenskaplig forskning (Research ethical principles in the arts and social sciences). Stockholm, Sweden: Swedish Research Council.

Halberstam, J. (2005). In a Queer time and place: Transgender bodies, subcultural lives. New York: New York University Press. 
Hammersley, M., \& Atkinson, P. (1983). Ethnography: principles in practice. London, England: Routledge.

Haupert, M. L., Gesselman, A. N., Moors, A. C., Fisher, H. E., \& Garcia, J. R. (2017). Prevalence of experiences with consensual nonmonogamous relationships: Findings from two national samples of single Americans. Journal of Sex \& Marital Therapy, 43(5), 424-440. https://doi.org/10.1080/009263X.2016.1178675.

Klesse, C. (2017) Theorizing multi-partner relationships and sexualities - Recent work on non-monogamy and polyamory. Sexualities. https://doi.org/10.1177/1363460717701691.

Newmahr, S. (2011). Playing on the edge. Sadomasochism, risk and intimacy. Bloomington, Indiana: Indiana University Press.

Phelan, S. (2001). Sexual strangers: Gays, lesbians and dilemmas of citizenship. Philadelphia, PA: Temple University Press.

Rambukkana, N. (2015). Fraught intimacies: non/monogamy in the public sphere. Vancouver, Canada: UBC Press.

Richters, J., de Visser, R. O., Rissel, C. E. Grulich, A. E., \& Smith, A. M. A. (2008). Demographic and psychosocial features of participants in bondage and discipline, "sadomasochism" or dominance and submission (BDSM): Data from a national survey. Journal of Sexual Medicine, 5(7), 1660-1668. https://doi.org/10.1111/j.17436109-2008.00795.x.

Séguin, L. J. (2017). The good, the bad, and the ugly: Lay attitudes and perceptions of polyamory. Sexualities, https://doi.org/10.1177/1363460717713382.

Sheff, E. (2005). Polyamorous women, sexual subjectivity and power. Journal of Contemporary Ethnography, 34(3), 251-283. https://doi.org/10.1177/0891241604274263.

Sheff, E., \& Hammers, C. (2011). The privilege of perversities: race, class and education among polyamorists and kinksters. Psychology \& Sexuality, 2(3), 198-223. https://doi.org/10.1080/19419899.2010.537674.
Sprott, R. A., \& Hadcock, B. B. (2017). Bisexuality, pansexuality, queer identity, and kink identity. Sexual and Relationship Therapy, 33(1-2), 214232. https://doi.org/10.1080/14681994.20171347616.

Taylor, G., \& Ussher, J. (2001). Making sense of S\&M: A discourse analytic account. Sexualities, 4(3), 293-314. https://doi.org/10.1177/136346001004003002.

Tweedy, A. E. (2011). Polyamory as a sexual orientation. University of Cincinnati Law Review, 79(4), 1461-1515. https://scholarship.law.uc.edu/uclr/vol79/iss4/5.

Weiss, M. (2011). Techniques of pleasure: BDSM and the circuits of sexuality. Durham, NC: Duke University Press.

Williams, D. J., Prior, E. E., Alvarado, T., Thomas, J. N., \& Christensen, M. C. (2016). Is bondage, dominance and submission, and sadomasochism recreational leisure? A descriptive exploratory investigation. Journal of Sexual Medicine, 13(7), 1091-1094. https://doi.org/10.1016/j.jsxm.2016.05.001.

Wismeijer, A. A. J., \& van Assen, M. A. L. M. (2013). Psychological characteristics of BDSM practitioners. Journal of Sexual Medicine, 10(8), 1943-1952. https://doi.org/10.1111/jsm.12192.

Wosick-Correa, K. (2010). Agreements, rules and agentic fidelity in polyamorous relationships. Psychology \& Sexuality, 1(1), 44-61. https://doi.org/10.1080/1949891003634471.

Yost, M. (2007). Sexual fantasies of S/M practitioners: the impact of gender and S/M role on fantasy content. In D. Langdridge \& M. J. Barker (Eds.), Safe, sane and consensual: Contemporary perspectives on sadomasochism, (pp. 135-154). New York: Palgrave MacMillan. 